Marquette University

e-Publications@Marquette

$10-2018$

\title{
Strain and Damage Self-Sensing of Basalt Fiber Reinforced Polymer Laminates Fabricated with Carbon Nanofibers/Epoxy Composites Under Tension
}

\author{
Yanlei Wang \\ Dalian University of Technology \\ Yongshuai Wang \\ Dalian University of Technology \\ Baolin Wan \\ Marquette University, baolin.wan@marquette.edu \\ Baoguo Han \\ Dalian University of Technology \\ Gaochuang Cai \\ University of Luxembourg
}

See next page for additional authors

Follow this and additional works at: https://epublications.marquette.edu/civengin_fac

Part of the Civil Engineering Commons

\section{Recommended Citation}

Wang, Yanlei; Wang, Yongshuai; Wan, Baolin; Han, Baoguo; Cai, Gaochuang; and Chang, Ruijuan, "Strain and Damage Self-Sensing of Basalt Fiber Reinforced Polymer Laminates Fabricated with Carbon Nanofibers/Epoxy Composites Under Tension" (2018). Civil and Environmental Engineering Faculty Research and Publications. 229.

https://epublications.marquette.edu/civengin_fac/229 


\section{Authors}

Yanlei Wang, Yongshuai Wang, Baolin Wan, Baoguo Han, Gaochuang Cai, and Ruijuan Chang

This article is available at e-Publications@Marquette: https://epublications.marquette.edu/civengin_fac/229 
Marquette University

e-Publications@Marquette

\title{
Civil Construction and Environmental Engineering Faculty Research and Publications/College of Engineering
}

This paper is NOT THE PUBLISHED VERSION; but the author's final, peer-reviewed manuscript. The published version may be accessed by following the link in th citation below.

Composites Part A: Applied Science and Manufacturing, Vol. 113 (October 2018): 40-52. DOI. This article is (C) Elsevier and permission has been granted for this version to appear in ePublications@Marquette. Elsevier does not grant permission for this article to be further copied/distributed or hosted elsewhere without the express permission from Elsevier.

\section{Strain and Damage Self-Sensing of Basalt Fiber Reinforced Polymer Laminates Fabricated with Carbon Nanofibers/Epoxy Composites Under Tension}

\author{
Yanlei Wang \\ State Key Laboratory of Coastal and Offshore Engineering, School of Civil Engineering, Dalian University of \\ Technology, Dalian, Liaoning 116024, China \\ Yongshuai Wang \\ State Key Laboratory of Coastal and Offshore Engineering, School of Civil Engineering, Dalian University of \\ Technology, Dalian, Liaoning 116024, China \\ Baolin Wan \\ Department of Civil, Construction and Environmental Engineering, Marquette University, Milwaukee, WI \\ Baoguo Han \\ State Key Laboratory of Coastal and Offshore Engineering, School of Civil Engineering, Dalian University of \\ Technology, Dalian, Liaoning 116024, China \\ Gaochuang Cai \\ Laboratory of Solid Structures, University of Luxembourg, Luxembourg L1359, Luxembourg \\ Ruijuan Chang
}


State Key Laboratory of Coastal and Offshore Engineering, School of Civil Engineering, Dalian University of Technology, Dalian, Liaoning 116024, China

\section{Abstract}

This study investigated the strain and damage self-sensing capabilities of basalt fiber reinforced polymer (BFRP) laminates fabricated with carbon nanofibers (CNFs)/epoxy composites subjected to tensile loadings. The conduction mechanisms based on the tunnel conduction and percolation conduction theories as well as the damage evolution were also explored. A compensation circuit with a half-bridge configuration was proposed. The results indicated the resistivity of the CNFs/BFRP laminates and CNFs/epoxy composites exhibited similar change rule, indicating that the conductive networks of CNFs/BFRP laminates were governed by CNFs/epoxy composites. With the increase of strain under monotonic tensile loading, the electrical resistance response could be classified into three stages corresponding to different damage modes. This confirmed CNFs/BFRP laminates have excellent self-sensing abilities to monitor their internal damages. Moreover, stable and repeatable strain self-sensing capacity of the CNFs/BFRP laminates was verified under cyclic tensile loading because the electrical resistance varied synchronously with the applied strain.

\section{Keywords}

A. Carbon nanotubes and nanofibers, A. Nanocomposites, B. Electrical properties, B. Mechanical properties

\section{Introduction}

Fiber reinforced polymer (FRP) composites are taking over traditional structural materials in various engineering fields due to their promising properties such as high specific modulus and strength, especially in lightweight structural applications [1], [2], [3]. However, FRP composites usually exhibit gradual degradation of mechanical properties during service because the formation of different levels of microscale damage including matrix microcracks, interfacial debonding, delamination and fiber breakage [4], [5]. The initiation and propagation of the microscale damage have considerable influence on the durability of FRP composites [6]. Even one small crack in the composites can cause their final failure after experiencing long-term service. Therefore, monitoring of damage initiation and propagation in FRP composites is of significant interest.

In contrast to plenty of researches focused on traditional FRP, such as carbon FRP (CFRP) and glass FRP (GFRP), relatively few researches on the properties of basalt FRP (BFRP) have been

undertaken [7], [8], [9], [10], [11], [12]. Basalt fiber (BF) has attracted much attention recently due to its good mechanical properties, low water absorption, strong fiber-resin adhesion, excellent tolerability to temperature and environmental actions against to glass fiber and much lower price relative to carbon fiber [13], [14], [15]. On account of the above numerous brilliant properties of BF, BFRP has been developed to be a potential substitute for GFRP and CFRP in some engineering fields. For instance, Refai et al. [7] researched the durability and fatigue of BFRP system. The results presented in their study indicated that the durability of BFRP system was not significantly affected after long-term immersion in saline and alkaline solutions, and the fatigue limit of BFRP system was higher than that of GFRP system. The study of Landucci et al. [8] demonstrated that BFRP could be used as reinforcement for novel fire shields due to its high fire resistance. Lopresto et al. [9] investigated the mechanical properties on comparable GFRP and BFRP laminates. The results showed that BFRP laminates, which had larger compressive and bending strength, exhibited better performance compared to GFRP laminates. This suggests possible applications of BFRP in some fields where GFRP are widely applied. The aforementioned studies [7], [8], [9], [10], [11], [12] proved that BFRP composites have broad application prospects in many engineering fields. Therefore, the strain and damage monitoring of BFRP composites during their service are in great demand. 
Over the last decades, in-situ electrical resistance measurement (ERM) has been regarded as a nondestructive method for strain and damage sensing. Considerable numbers of researches have been performed to study the strain and damage monitoring of CFRP composites by using ERM [16], [17], [18], [19], [20]. For example, Wang et al. [18], [20] studied the static/fatigue damage and dynamic strain monitoring in cross-ply CFRP composites by using direct current measurement techniques. The relative change in resistance $\Delta R / R_{0}$ was used for strain and damage sensing under static and dynamic loading. However, this method is not available for the electrically insulating GFRP and BFRP composites. Fortunately, with the rapid development of nanotechnology, the advent of carbon nanomaterials, such as carbon nanotubes (CNTs) and carbon nanofibers (CNFs) and graphene, has enable the insulating composites turned into electrically conductive ones [21], [22], [23]. In addition, as conductive fillers for FRP composites, nanomaterials can not only improve the mechanical properties of FRP composites, but also endow sensing capabilities to FRP composites [24], [25], [26], [27], [28]. For instance, Wang et al. [28] introduced few layer graphene (FLG) into insulating poly styrene-butadienestyrene (SBS) to fabricate the highly sensitive and stretchable strain sensor. Their results reveal that the SBS/FLG fiber based strain sensor possess superior performance, including wide workable strain range $(>110 \%)$, excellent sensitivity (gauge factor of 160 at a strain of $50 \%$ and of 2546 at a strain of 100\%), and durability. Numerous studies have demonstrated that the combination of the ERM technique and conductive networks provided by the carbon nanomaterials surrounding the insulting fibers was an effective technique for monitoring the strain and damage of GFRP composites [29], [30], [31], [32], [33]. In the study of Li et al. [29], a small amount of CNT-Al $\mathrm{O}_{3}$ hybrids were introduced into GFRP composites to create an in-situ sensor to monitor the damage initiation and propagation under mechanical loading. Their results suggested that the electrical resistance response could be classified into different distinguished stages to identify various failure modes of FRP composites.

In contrast, relatively few researchers investigated the self-sensing application of strain and damage of BFRP composites [13]. Hao et al. [13] studied the modification of BF using pyrolytic carbon coating for sensing applications. Analysis of the stress-strain curves along with the corresponding electrical resistance of the sample confirmed that BF with pyrolytic carbon coating could be used as a sensor to monitor the damage of composite structures. However, with regard to the growth of conductive fillers on fiber surface, it was most sensitive to the fracture of the loading-carrying fibers while provided less information on the development of cracks in matrix, where the microscale damages were initiated. Therefore, it is worth to study the self-sensing behaviors of BFRP laminates infused with the CNFs/epoxy composites, which can in-situ monitor not only the overall strain and damages of the BFRP laminates, but also the microscale damages of their matrix.

In this study, different contents of CNFs were dispersed into epoxy matrix and infused into basalt fiber fabric to form the conductive networks for strain and damage self-sensing of BFRP laminates. The electrical properties of CNFs/epoxy composites and CNFs/BFRP laminates were investigated first, followed by the description of conductive mechanisms with different contents of CNFs. Secondly, a compensation circuit corresponding to a half-bridge configuration was proposed to eliminate the influence of temperature on electrical resistivity of the specimens. Finally, the electrical resistances of CNFs/BFRP laminates under the monotonic and cyclic tensile loadings were tracked to explore their strain and damage self-sensing abilities.

\section{Experimental program}

\subsection{Materials}

Unidirectional woven basalt fiber fabric with surface density of $300 \mathrm{~g} / \mathrm{m}^{2}$ was purchased from Sichuan Aerospace Tuoxin Basalt Industry Co., Ltd., China. Pyrograf-III PR-24-XT-HHT (manufactured by Pyrograf Products, Inc., USA), which are heat treated CNFs with a diameter of 70-200 nm and a length of 50-200 $\mu \mathrm{m}$, were employed as the conductive nanofillers. The epoxy resin used as the matrix of the nanocomposites was produced by Tianjin Swancor Wind Power Materials Co., Ltd., China. SWANCOR 2511-1A and SWANCOR 2511-1BS, with a ratio of 
10:3 in weight or 30:11 in volume, is the main and curing agents of the epoxy, respectively. The epoxy resin has low viscosity, moderate gel time, nice mechanical properties, high heat deflection temperature (HDT), and good wettability to CNFs. The CNFs in the amount of $0.2 \%, 0.5 \%, 1.0 \%, 1.5 \%, 2.0 \%$, and $3.0 \%$ by weight of epoxy resin (i.e., $0.116 \%, 0.29 \%, 0.58 \%, 0.87 \%, 1.16 \%$, and $1.74 \%$ by volume of epoxy resin, respectively) were used in this research. The corresponding $C N F s / e p o x y$ composites are called $C_{0.2}, C_{0.5}, C_{1.0}, C_{1.5}, C_{2.0}$, and $C_{3.0}$, respectively, in this paper. Similarly, the corresponding CNFs/BFRP laminates are called $L_{0.2}, L_{0.5}, L_{1.0}, L_{1.5}, L_{2.0}$, and $L_{3.0}$, respectively. Acetone was used as diluting agent in the amount of $2 \%$ by volume of CNFs/epoxy composite. Copper sheet with a width of $5 \mathrm{~mm}$ was used as the electrode. The conductive copper paint was used to ensure good contact between the specimens and the electrodes.

\subsection{Specimens}

In this study, mechanical stirring and ultrasonic treatment were used to disperse CNFs into epoxy matrix. In order to facilitate the dispersion of CNFs, CNFs was put in an oven at $60^{\circ} \mathrm{C}$ for 20 min to remove possible moisture in them. The CNFs/epoxy composites and CNFs/BFRP laminates were fabricated by the following procedure (illustrated in Fig. 1): (1) Different amounts of CNFs (0.2 wt\%, 0.5 wt\%, 1.0 wt\%, 1.5 wt\%, 2.0 wt\%, and $3.0 \mathrm{wt} \%$ ) were dispersed into acetone by using a mechanical stirrer (Model SFJ-400, Shanghai Modern Environmental Engineering Technology Co., Ltd., China) at high speed (1500 r/min) for $10 \mathrm{~min}$, and then sonicated by Branson 2800 Ultrasonic Cleaner (Model 2510 E-DTH, 100 W 40KHz, Branson Ultrasonic Co., Ltd., USA) for $8 \mathrm{~h}$ at about $20^{\circ} \mathrm{C}$ to get the CNFs-acetone mixture. The purpose of setting the temperature at about $20{ }^{\circ} \mathrm{C}$ was to reduce the volatilization of acetone. In addition, the water temperature was kept around $20^{\circ} \mathrm{C}$ by constantly changing the water in the ultrasonic instrument. (2) Heated (at $60^{\circ} \mathrm{C}$ for $2 \mathrm{~min}$ ) SWANCOR $2511-1 \mathrm{~A}$ was dissolved in the CNFs-acetone mixture via stirring at high speed for $20 \mathrm{~min}$ and ultrasonically dispersing at $60^{\circ} \mathrm{C}$ for $8 \mathrm{~h}$ to get a slurry-like mixture. The purpose of re-use of ultrasonic treatment was to promote dispersion of CNFs in the resin. (3) The mixture was placed in a vacuum oven (Model DZ-2BC, Tianjin Taisite Instrument Co., Ltd., China) to remove acetone and air bubbles. (4) After the mixture was cooled, the curing agent (SWANCOR 2511-1BS) was added and mixed by mechanical stirring at low speed ( $500 \mathrm{r} / \mathrm{min}$ ) for $5 \mathrm{~min}$ to get the CNFs/epoxy suspension. The purpose of low speed stirring was to create bubbles in the mixture as little as possible. (5) If the CNFs/epoxy composite specimens were to be fabricated, the prepared CNFs/epoxy suspension was poured into silicone molds with dog bone shape. If the unidirectional CNFs/BFRP laminates were to be made, the prepared CNFs/epoxy suspensions were applied into four layers of unidirectional basalt fiber fabrics, and the laminate specimens were made by using wet lay-up technique. (6) All CNFs/epoxy composites and CNFs/BFRP laminates were pre-cured at room temperature for $24 \mathrm{~h}$ followed by a post-cure for an additional $24 \mathrm{~h}$ at $60^{\circ} \mathrm{C}$. (7) The CNFs/BFRP test specimens with dimensions of $250 \times 20 \times 1.5 \mathrm{~mm}$ were cut from the cured CNFs/BFRP laminates and their surface was polished prior to measurement. The copper sheets were glued at the surfaces of the CNFs/BFRP laminate and CNFs/epoxy composite specimens using a conductive copper paint. The schematic in Fig. 2 presents the dimensions of the specimens and the layout of the electrodes. Moreover, as shown in Fig. 2, the width of the copper electrode is $5 \mathrm{~mm}$. The separations between the two electrodes (gauge length) are $25 \mathrm{~mm}$ and $60 \mathrm{~mm}$ for CNFs/epoxy composite and CNFs/BFRP laminates, respectively.

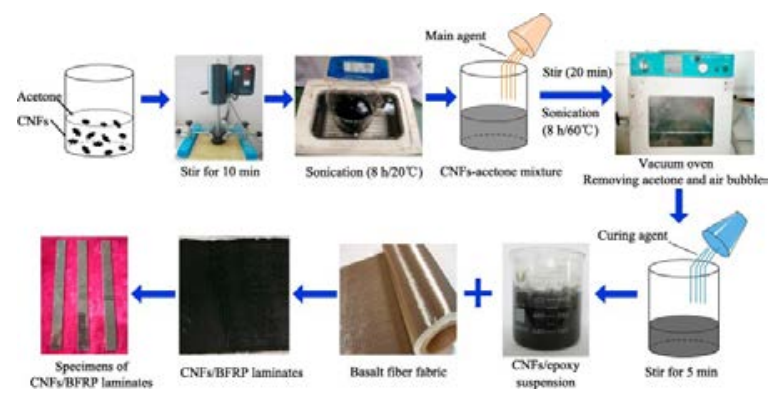


Fig. 1. Preparation process of the CNFs/BFRP laminates. (For interpretation of the references to colour in this figure legend, the reader is referred to the web version of this article.)
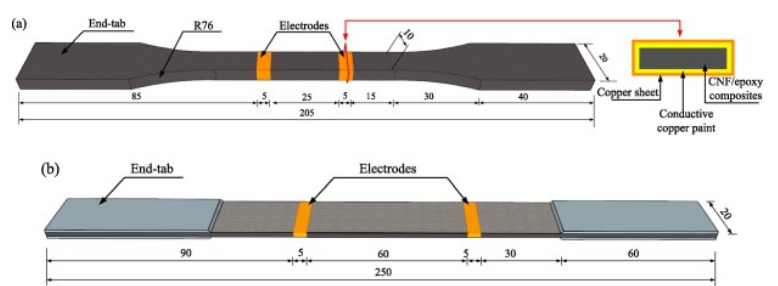

Fig. 2. Schematic of (a) CNFs/epoxy composites and (b) CNFs/BFRP laminates. (Units in mm). (For interpretation of the references to colour in this figure legend, the reader is referred to the web version of this article.)

\subsection{Measurements}

\subsubsection{Electrical properties}

Three samples of each type of CNFs/BFRP laminate and CNF/epoxy composites were tested for the electrical properties of the composites and laminates containing different CNFs contents ( 0 wt $\%, 0.2 \mathrm{wt} \%, 0.5 \mathrm{wt} \%$, $1.0 \mathrm{wt} \%, 1.5 \mathrm{wt} \%, 2.0 \mathrm{wt} \%$, and $3.0 \mathrm{wt} \%)$. The direct current (DC) electrical resistances of the specimens without loading were measured by two-electrode method using a Keithley 2100 digital multimeter (Keithley Instruments Inc., USA) by setting a constant voltage. The two copper sheets (shown in Fig. 2) served as the electrical contacts for conducting the current and measuring the voltage, simultaneously. The electrical resistivity (the resistance per unit volume in the bulk material), $\rho$, is determined by

$$
\text { (1) } \rho=R \frac{A}{L}
$$

where $R$ is the measured electrical resistance, $A$ is the cross-sectional area of the sample, and $L$ is the separation between the two electrodes.

\subsubsection{Temperature effect}

Temperature has a significant influence on the CNFs/BFRP laminates, so the effect of temperature on electrical resistivity was investigated. According to the results of the electrical property tests, the BFRP laminates containing three contents of CNFs $(0.5 \mathrm{wt} \%, 1.0 \mathrm{wt} \%$ and $1.5 \mathrm{wt} \%)$, which are close to the percolation threshold of CNFs, were selected for temperature effect tests. Three specimens for each type of CNFs/BFRP laminates were tested for this purpose. Before the tests of temperature effect, the specimens were heated to $60^{\circ} \mathrm{C}$ and isothermal treated for $5 \mathrm{~min}$, and then cooled to $20^{\circ} \mathrm{C}$ to eliminate the effect of thermal history developed during the preparation process. The specimens were placed in the high-low temperature tester (Lin Pin Co., Ltd., China), and the temperature range was set from -30 to $60^{\circ} \mathrm{C}$ at a heating rate of $2{ }^{\circ} \mathrm{C} / \mathrm{min}$. The thermosensitive properties of CNFs/BFRP laminates were measured using two-electrode method by employing the Keithley 2100 digital multimeter in the process of temperature changes. In order to investigate the repeatability of the thermosensitive properties, the electric resistivity measurements were conducted through three heating-cooling cycles.

\subsubsection{Self-sensing properties}

Monotonic tensile and cyclic tensile tests were conducted to investigate the feasibility and repeatability of damage and strain self-sensing abilities of the CNFs/BFRP laminates and CNFs/epoxy composites. Six specimens of $L_{0.5}, L_{1.0}$ and $L_{1.5}$ CNFs/BFRP laminates and six specimens of $C_{0.5}, C_{1.0}$ and $C_{1.5}$ CNFs/epoxy composites were used for self-sensing properties tests. For each type of specimens, three were tested under monotonic tensile loads to verify the damage self-sensing capabilities, and the remaining three were subjected to constant amplitude cyclic loading to test their strain self-sensing behaviors. The tests were conducted by applying uniaxial 
tensile loads and simultaneously measuring the strain and the electrical resistance of the specimens. All loads were applied through an electronic universal testing machine (Model WDE-200E, Jinan Gold Testing Machines Inc., China), with the strain rates of $0.67 \% / \mathrm{min}$ and $0.43 \% / \mathrm{min}$ for CNFs/epoxy composites and CNFs/BFRP laminates, respectively. For constant cyclic tests, there were two loading paths. Both paths consisted of five loading-unloading cycles with a minimum strain of $0 \%$, while the maximum strains of $0.5 \%$ and $1.0 \%$ were applied during loading paths I and II, respectively. The CNFs/epoxy composites were tested by loading path I, while the CNFs/BFRP laminates were tested by loading path II. The two-electrode method was chosen to measure the electrical resistance rather than the four-electrode method due to the better suitability in terms of implementation [34]. During the test process, the DC resistance was tested via the Keithley 2100 digital multimeter and the strain was monitored by one extensometer at the test zone of the specimens. The experimental setup of self-sensing test is shown in Fig. 3.

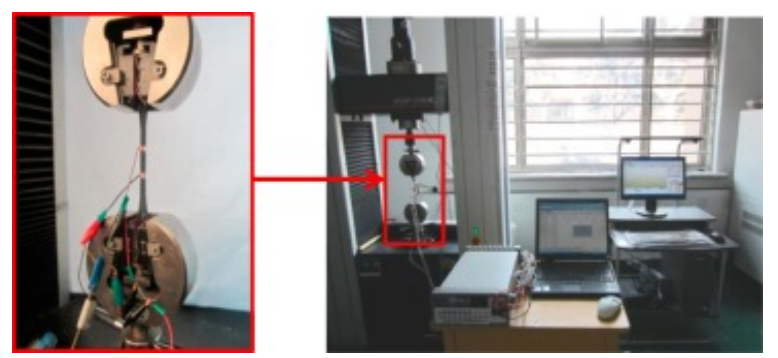

Fig. 3. Experimental setup of self-sensing test. (For interpretation of the references to colour in this figure legend, the reader is referred to the web version of this article.)

Since the deformation of the specimens under tension is pretty small, the changes in the separation $(L)$ between the two electrodes can be neglected. Therefore, the fractional change in electrical resistivity (FCR), $f$, is equivalent to the fractional change in electrical resistance:

(2) $f=\frac{\Delta \rho}{\rho_{0}}=\frac{\Delta R \times A / L}{R_{0} \times A / L}=\frac{\Delta R}{R_{0}}=\frac{R_{t}-R_{0}}{R_{0}}$

where $\Delta \rho$ (or $\Delta R$ ) is the change in electrical resistivity (or resistance); $\rho_{0}$ (or $R_{0}$ ) is the initial resistivity (or resistance) of the specimens without loading; and $R_{t}$ is the resistance at time $t$ during the test.

\subsubsection{Microstructure characterization}

The microstructures of the fabricated CNFs/epoxy composites and CNFs/BFRP laminates were observed by a scanning electron microscope (SEM) (Nova NANOSEM450, FEI Inc., USA) and an optical microscopy to investigate the CNFs dispersion in matrix and failure mechanisms. The samples used for microscopic analysis were cut from the failure regions of the fractured specimens. In order to reduce the variation among microstructure images, five samples were investigated for each group of specimens with identical CNFs content. Before the SEM observation, the fractured surfaces were sputtered with a thin layer of gold for better imaging.

\section{Results and discussions}

\subsection{Microstructure}

It is noted that the samples with same content of CNFs had similar microscopic characters at the fracture surface and only representative SEM images of the microstructure were shown in this study. The SEM images of CNFs/epoxy composites filled with different amount of CNFs (0 wt\%, 0.5 wt\%, $1.0 \mathrm{wt} \%$ and $2.0 \mathrm{wt} \%$ ) are shown in Fig. 4a-d. Comparison of the SEM images reveals that CNFs were dispersed more uniformly in the epoxy matrix when the content was relative low ( $\underline{F i g .4 \mathrm{~b}}$ and $\mathrm{C}$ ), while a little more agglomerations of CNFs occurred when the content of CNFs was relative high (Fig. 4d). From the SEM images of CNFs/BFRP laminates with 
$1.0 \mathrm{wt} \%$ and $1.5 \mathrm{wt} \%$ of CNFs shown in Fig. $4 \mathrm{e}$ and $\mathrm{f}$, it can be seen that the basalt fibers are surrounded in the center by CNFs/epoxy nanocomposites, showing a harmonious hybrid structure. Moreover, according to the SEM images of CNFs/BFRP laminates, most CNFs can be uniformly dispersed in the epoxy matrix and penetrate the basalt fiber bundles, forming conductive networks throughout the BFRP laminates. The achievement of the good dispersion of CNFs is significant for enhancing the nanocomposites' properties, especially the piezoresistive reproducibility and the mechanical properties.

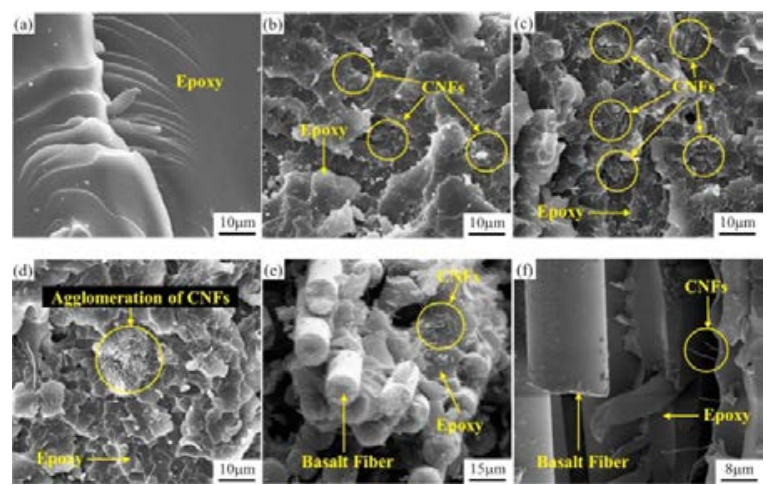

Fig. 4. SEM images of CNFs/epoxy composites filled with (a) $0 \mathrm{wt} \%$, (b) $0.5 \mathrm{wt} \%$, (c) $1.0 \mathrm{wt} \%$ and (d) $2.0 \mathrm{wt} \%$ of CNFs; SEM images of CNFs/BFRP laminates filled with (e) $1.0 \mathrm{wt} \%$ and (f) $1.5 \mathrm{wt} \%$ of CNFs. (For interpretation of the references to colour in this figure legend, the reader is referred to the web version of this article.)

\subsection{Electrical properties of CNFs/epoxy composites and CNFs/BFRP laminates}

\subsubsection{Percolation threshold}

Fig. 5 presents the average values of the electrical resistivity of the CNFs/epoxy composites and CNFs/BFRP laminates containing different contents of CNFs. It is observed that a significant decrease of resistivity when the content of CNFs increased from 0 to $1.0 \mathrm{wt} \%$, and then a much smaller decrease rate at higher content of CNFs. The content range where the resistivity varied drastically is called the percolation threshold zone. Therefore, the possible percolation threshold zone of CNFs ranges from $0.2 \mathrm{wt} \%$ to $1.0 \mathrm{wt} \%$. In order to confirm the percolation threshold of CNFs in CNFs/epoxy composites and CNFs/BFRP laminates by theoretical investigations, the typical power law was investigated [29]:

(3) $\sigma=1 / \rho=k\left(\varphi-\varphi_{c}\right)^{t}$ for $\varphi \geqslant \varphi_{c}$

where $\sigma$ is the electrical conductivity of the specimen, $k$ is a constant, $\varphi$ is the weight fraction of CNFs, $\varphi_{c}$ is the critical weight fraction of CNFs, i.e., the percolation threshold (when $\varphi$ is larger than $\varphi_{c}$, CNFs can form conductive paths in the nanocomposite), and $t$ is the critical exponent related to the dimensionality of the system, which depends on the geometry of the conducting network. The best fits of the experimental resistivity data to log-log plots of the power law (the inset in Fig. 5) gives the values of $\varphi_{c}$ for CNFs/epoxy composites and CNFs/BFRP laminates are $0.34 \mathrm{wt} \%$ and $0.32 \mathrm{wt} \%$, respectively. The critical exponents of them are 1.87 and 1.60 , respectively, which are close to that of a three-dimensional random system $(t=1.94)$ [35]. However, the critical exponent $t$ of CNFs/BFRP laminates is 1.60 (less than 1.87), which indicates that the three-dimensional random distribution of the conductive networks in the CNFs/BFRP laminate are worse than that of the CNFs/epoxy composites. The reason is that insulating basalt fibers have an impediment to the formation of conductive networks. In addition, the plots in Fig. 5 also reveal that CNFs/BFRP laminates have higher resistivity than that of CNFs/epoxy composites when they contain same content of CNFs. When CNF/epoxy suspensions are incorporated into basalt fiber fabric, insulating basalt fibers have an impediment to the formation of conductive networks (shown in Fig. 6), leading to a lower electrical conductivity. This may be the main reason that the CNFs/BFRP laminates exhibit higher resistivity shown in Fig. 5. 


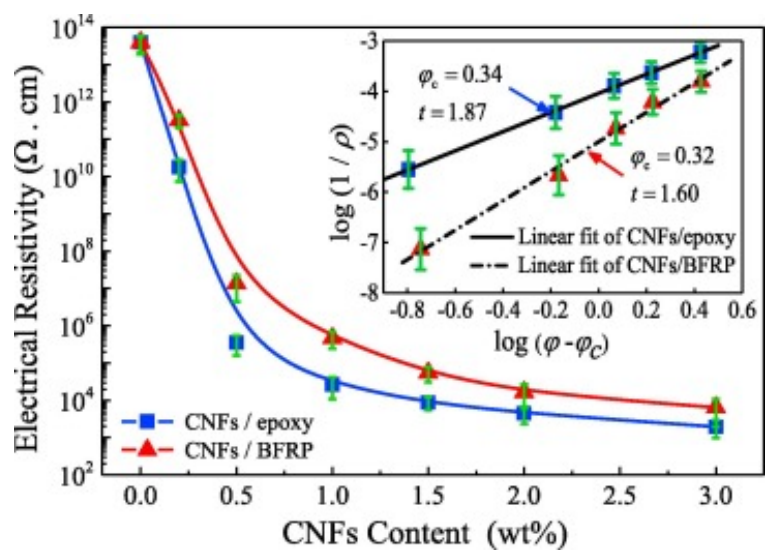

Fig. 5. Electrical resistivity of CNFs/epoxy composites and CNFs/BFRP laminates as a function of CNFs content. (Inset: logarithm of conductivity as a function of logarithm of reduced weight fraction). (For interpretation of the references to colour in this figure legend, the reader is referred to the web version of this article.)
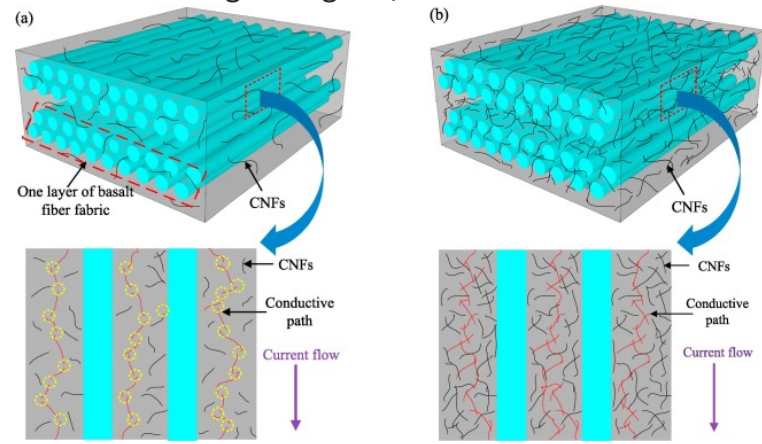

Fig. 6. Schematic diagram of conductive mechanisms with different contents of CNFs: (a) tunneling conduction; (b) contacting conduction. (For interpretation of the references to colour in this figure legend, the reader is referred to the web version of this article.)

\subsubsection{Conductivity mechanisms of CNFs/BFRP laminates}

The results in Fig. 5 agree with the paths theory, i.e., the number of conduction paths between the CNFs increases in the nanocomposites with the increase of the CNFs content. When the contents of CNFs in CNFs/BFRP laminates are relative low (below $0.32 \mathrm{wt} \%$ ), tunneling conduction [36], [37] is the major cause for the decrease of laminates' resistivity as the increase of the CNFs contents. The electrical conductivity is low because there are a few CNFs and almost no contacts between them as show in Fig. 6a. As the increase of the CNFs content, the gaps between the CNFs become narrower and electronic charge can be easier to transport between CNFs, leading to the decrease of the resistivity in CNFs/BFRP laminates. When the contents of CNFs are relative large (higher than $0.32 \mathrm{wt} \%$ ), the electrical conductivity of the laminates increases remarkably by the percolation conduction [38], [39], also called contacting conduction, as shown in Fig. 6b. In this case, the complete electrically conductive paths connect by some CNFs contacting each other (red paths in Fig. 6b), which may be considered as the major cause for the decrease of the electrical resistivity of the laminates as the increase of the CNFs content. It should be noted that two rows of fibers are used to represent a layer of fiber fabric in the schematic. Moreover, a little more agglomerations of CNFs occurred when the contents of CNFs was relative high, which would affect the electrical and mechanical properties of the composites.

\subsection{Effect of temperature on electrical resistivity of CNFs/BFRP laminates}

Temperature affects the resistivity of CNFs/BFRP laminates by three ways: (1) thermal expansion of the epoxy matrix (control factor), the basalt fiber and the CNFs, (2) thermal fluctuation and hopping effect induced tunneling conduction [40], [41], (3) the change of CNFs conductivity. However, the third one can be ignored as it is relatively small compared to the other two ways [42]. Because the thermal expansion coefficients of basalt 
fiber $\left(6.5-8.0 \times 10^{-6} /{ }^{\circ} \mathrm{C}\right.$ ) and CNFs (below $1.0 \times 10^{-6} /{ }^{\circ} \mathrm{C}$ ) are much smaller than that of epoxy (about $\left.50 \times 10^{-6} /{ }^{\circ} \mathrm{C}\right)$, the thermal expansion of basalt fiber and CNFs can be neglected. With the increase of temperature, on one hand thermal expansion causes the increase of tunneling gap, and on the other hand the thermal fluctuation and hopping effect induces the increase of tunneling conduction. However, these two factors have opposite effects on FCR of CNFs/BFRP laminates.

Temperature cycling test consisting of three heating-cooling cycles with the range of $-30-60{ }^{\circ} \mathrm{C}$ was performed. The FCR values of $L_{0.5}, L_{1.0}$ and $L_{1.5}$ with temperature variation are shown in Fig. 7 , and the reference resistances for this experiment are the resistances of the laminates at $-30^{\circ} \mathrm{C}$. The line charts show the average values with error bars obtained from three samples for each type of the laminates. At low temperature $\left(T<-10{ }^{\circ} \mathrm{C}\right)$, different trends of the curves were observed in different laminates. The resistivity of $\mathrm{L}_{1.0}$ and $\mathrm{L}_{1.5}$ increased with the increase of temperature. However, the resistivity of $L_{0.5}$ decreased when the temperature increased from $-30^{\circ} \mathrm{C}$ to $-10{ }^{\circ} \mathrm{C}$.
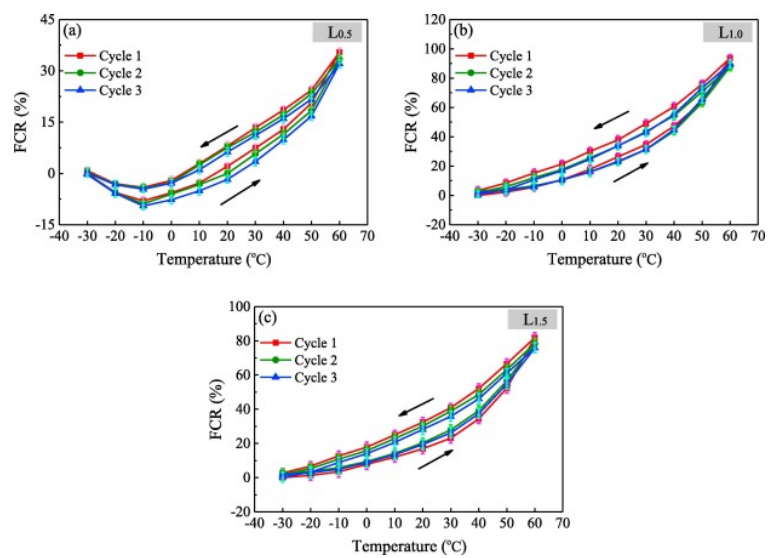

Fig. 7. Responses of FCR to temperature for (a) $L_{0.5}$, (b) $L_{1.0}$ and (c) $L_{1.5 .}$. (For interpretation of the references to colour in this figure legend, the reader is referred to the web version of this article.)

The result of $L_{0.5}$ indicates that the effect of thermal fluctuation and hopping effect induced tunneling conduction is dominant when the CNFs content is relative low, especially at low temperatures where the strain of epoxy resulted from thermal expansion is small. When the temperature was above $-10{ }^{\circ} \mathrm{C}$, it is noticeable that FCR increased with the increase of temperature in all cases. The cause is that the thermal expansion of the epoxy matrix induced obvious increase of the distance between CNFs, leading to the increase of the resistivity. In addition, Fig. 7 also shows that the CNFs content can change the FCR value of the sample with the variation of temperature. As the temperature increases, the thermal expansion of the epoxy induced obvious increase of the distance between the CNFs, leading to the increase of the resistivity. Meanwhile, thermal fluctuation and hopping effect induce the increase of the tunneling conductive paths, which results in the decrease of the resistivity. Therefore, there are two opposite factors mainly influencing the change of resistivity. When the CNFs content is relative low $(0.5 \mathrm{wt} \%$ in this study), the number of original conductive paths in the laminates is less than those in the laminates with more CNFs. As a result, the FCR of $L_{0.5}$ is lower than others. When the amount of CNFs is large, the thermal expansion causes a large number of CNFs to increase the distances among them, resulting in larger FCR for $L_{1.0}$ and $L_{1.5}$. The plots in Fig. 7 demonstrate a high temperature dependence of CNFs/BFRP laminates, while a slight hysteresis was observed in all specimens. The reason for the hysteresis could be the slow volume expansion/contraction processes of the epoxy, causing the internal conductive network could not be restored in time.

Temperature compensation is necessary due to the high temperature dependence of the CNFs/BFRP laminates. One of the effective ways to eliminate the influence of temperature on resistivity of the laminates is to set up a 
compensation circuit. The mechanism of the compensation circuit is shown in Fig. 8. In Fig. 8, $R_{T}$ represents the test laminate and $R_{c}$ represents the compensation laminate, which is not subjected to the load. $R_{1}$ and $R_{2}$ are the precision resistors used to balance the bridge voltage. The compensation circuit has the Wheatstone half-bridge configuration. The conditions for effective temperature compensation with a Wheatstone bridge are that both the test and compensation laminates have the same temperature coefficient and nominal resistance values.

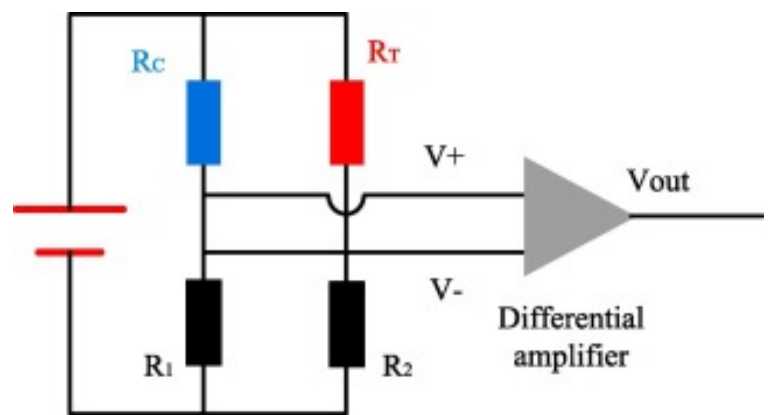

Fig. 8. Schematic of the compensation circuit. (For interpretation of the references to colour in this figure legend, the reader is referred to the web version of this article.)

In order to verify the validity of the compensation circuit, both the test and compensation CNFs/BFRP laminates of $L_{0.5}, L_{1.0}$ and $L_{1.5}$ were placed in the environment with same temperature, and the FCR values of the compensation circuit were tested as the changes of the temperature. Table 1 reports the FCR values of CNFs/BFRP laminates with temperature compensation. The data in the table are the average values obtained from three samples for each type of CNFs/BFRP laminates. In the entire temperature range from $-30{ }^{\circ} \mathrm{C}$ to $60{ }^{\circ} \mathrm{C}$, the FCR value of the compensation circuit was below $0.5 \%$, which is much smaller than that of one laminate (shown in Fig. 7). It can be observed from Table 1 that the compensation circuit can be used to effectively eliminate the influence of temperature on the FCR values of CNFs/BFRP laminates.

Table 1. FCR values of CNFs/BFRP laminates with temperature compensation (\%).

\begin{tabular}{|l|l|l|l|l|l|l|l|l|l|l|}
\hline $\boldsymbol{T}$ & $-30{ }^{\circ} \mathrm{C}$ & $-20{ }^{\circ} \mathrm{C}$ & $-10{ }^{\circ} \mathrm{C}$ & $0{ }^{\circ} \mathrm{C}$ & $10^{\circ} \mathrm{C}$ & $20{ }^{\circ} \mathrm{C}$ & $30{ }^{\circ} \mathrm{C}$ & $40{ }^{\circ} \mathrm{C}$ & $50{ }^{\circ} \mathrm{C}$ & $60{ }^{\circ} \mathrm{C}$ \\
\hline $\mathrm{L}_{0.5}$ & 0 & 0.01 & 0.22 & 0.21 & -0.10 & -0.31 & 0.35 & 0.32 & -0.28 & 0.10 \\
\hline $\mathrm{L}_{1.0}$ & 0 & 0.05 & -0.06 & 0.15 & 0.20 & -0.11 & -0.10 & 0.28 & -0.22 & 0.09 \\
\hline $\mathrm{L}_{1.5}$ & 0 & -0.13 & 0.12 & 0.09 & 0.33 & -0.25 & 0.21 & -0.34 & 0.18 & -0.13 \\
\hline
\end{tabular}

\subsection{Self-sensing properties of CNFs/epoxy composites and CNFs/BFRP laminates}

\subsubsection{Damage self-sensing under monotonic tensile loading}

In order to compare the self-sensing properties of CNFs/epoxy composites and CNFs/BFRP laminates, both of them were subjected to monotonic tensile loading till failures. Fig. 9 shows the typical responses of FCR and stress to strain under monotonic tensile loading for the CNFs/epoxy composites containing three contents of CNFs. It can be observed that the ultimate tensile strength of $C_{1.0}$ was not only larger than $C_{0.5}$ but also larger

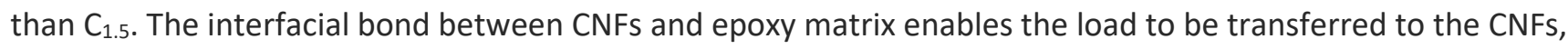
which is an important factor for enhancing the mechanical properties of the composites. Meanwhile, the absorbing energy by overcoming pull-out of CNFs also results in an increase of tensile strength of the composites. However, when the contents of CNFs are relative high, the inhomogeneous dispersion of CNFs leads to the appearance of agglomerations of CNFs (shown in Fig. 4). The agglomerations of CNFs cause the defects in the composites, resulting in a decrease of the tensile strength of $\mathrm{C}_{1.5}$. In addition, different trends of FCR-strain curves are observed in three types of CNFs/epoxy composites. 

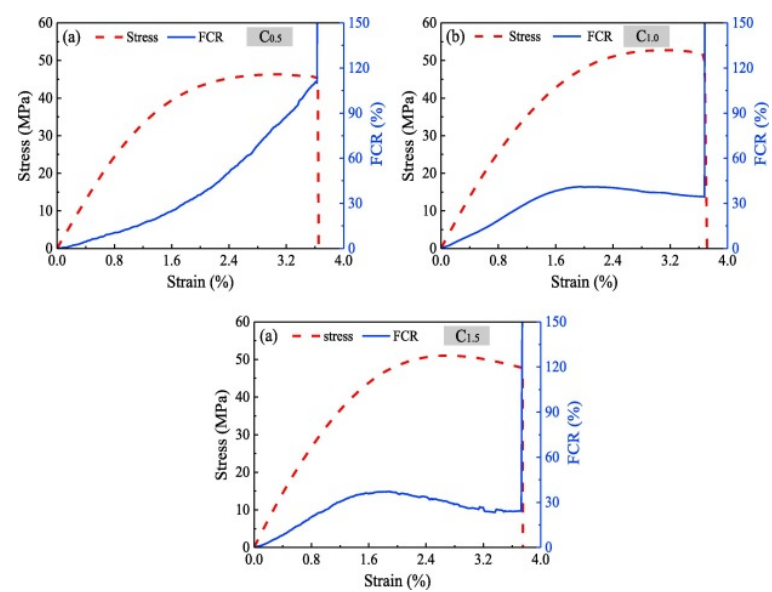

Fig. 9. Responses of FCR and stress to strain under monotonic tensile loading for (a) $C_{0.5}$, (b) $C_{1.0}$ and (c) $C_{1.5 .}$ (For interpretation of the references to colour in this figure legend, the reader is referred to the web version of this article.)

Fig. 9a presents the FCR of $\mathrm{C}_{0.5}$ increases continuously with the increase of applied strain. In particularly, the FCR of $\mathrm{C}_{0.5}$ shows a nearly linear dependence on the applied strain up to about $1.0 \%$, while nonlinear responses are observed under larger deformations. At the strain about 3.6\%, the electrical resistivity of $\mathrm{C}_{0.5}$ jumped to infinity, indicating the failure of the sample. The first linear increase of FCR with the increase of the applied strain in low strain zone (about $0 \%-1.0 \%$ ) is due to the initial elastic deformation of the CNFs/epoxy composites. The subsequent nonlinear increase of FCR as the increase of the applied strain is attributed to microcracks initiated from the randomly distributed flaws in the CNFs/epoxy composites. As the CNFs content of $\mathrm{C}_{0.5}$ is relative low, tunneling effect plays a dominant role on electrical conductive mechanism at this stage. The clear exponential growth trend of the FCR indicates that sparse conductive networks were destroyed gradually by the emergence and development of microcracks in $\mathrm{C}_{0.5}$.

For the specimens of $C_{1.0}$ and $C_{1.5}$, the values of FCR increased first and then decreased slowly with the increasing strain before the final fracture of the samples (shown in Fig. $9 \mathrm{~b}$ and c). Since the contents of CNFs in $\mathrm{C}_{1.0}$ and $\mathrm{C}_{1.5}$ were much larger than the percolation threshold $(0.34 \mathrm{wt} \%)$, abundant conductive networks were established in the two types of CNFs/epoxy composites, leading to the different trends of FCR-strain curves in $\mathrm{C}_{1.0}$ and $\mathrm{C}_{1.5}$ compared with that of $\mathrm{C}_{0.5}$. On the one hand, the emergence and propagation of the microcracks could further accelerate the breaking of the original conductive networks, causing the significant increase of resistivity in the composites. On the other hand, the Poisson contraction of the epoxy matrix beyond elastic region plays an important role on the establishment of new conductive networks, leading to a decrease of the resistivities of $C_{1.0}$ and $C_{1.5}$ [29]. However, the latter reason has a much greater effect on the resistivity change than the former reason, which can be used to explain the trend of FCR-strain curves shown in Fig. $9 \mathrm{~b}$ and c.

Comparing the three plots in Fig. 9 , it was found that the FCR of $\mathrm{C}_{0.5}$ increase continuously with the increasing strain, which was unable to provide an early warning for the destruction of the composites. However, the composites with low contents of CNFs still can be used for strain self-sensing based on their FCR-strain curves. In contrast, $C_{1.0}$ and $C_{1.5}$ not only have the ability to identify the elastic and plastic deformation regions of the composites, but also provide an early warning sign before the failure because the FCR responses have a clear turning point with the increase of strain.

Fig. 10 shows the typical stress-strain and FCR-strain curves of three types of CNFs/BFRP laminates under monotonic tensile loading until their failure. It can be observed that the ultimate tensile strength of $L_{1.5}$ was lower than that of $\mathrm{L}_{1.0}$, which is similar to the relation between $\mathrm{C}_{1.5}$ and $\mathrm{C}_{1.0}$. The reason may be that the increased agglomerations of CNFs in $\mathrm{L}_{1.5}$ with relatively high CNFs contents caused more defects within the 
laminate, resulting in the decrease of the mechanical enhancement effect of CNFs to the laminates. Similar trends of FCR-strain curves can be observed in CNF/BFRP laminates and CNFs/epoxy composites as shown in Fig. $\underline{9}$, Fig. 10, which further confirms that the resistance change of CNF/BFRP laminates was due to the variation of conductive networks in CNFs/epoxy composites. The FCR-strain curve of L0.5 shown in Fig. 10a is different from that of $L_{1.0}$ and $L_{1.5}$ because $L_{0.5}$ has a different conduction mechanism, which is similar to that of $C_{0.5}$. Because the load is mainly carried by basalt fibers in CNF/BFRP laminates, the stress-strain curves exhibit a linear relationship as shown in Fig. 10. However, the conductive networks formed by CNF/epoxy matrix in $\mathrm{L}_{1.0}$ and $\mathrm{L}_{1.5}$ were successively destroyed with the increasing strain during monotonic loading. Therefore, the FCR-strain response shows nonlinear relationship (Fig. 10b and c). In addition, it can be observed from Fig. 10b and c that the FCR-strain curves of $L_{1.0}$ and $L_{1.5}$ can be classified into three stages corresponding to the different damage modes, which is discussed in detail in following.
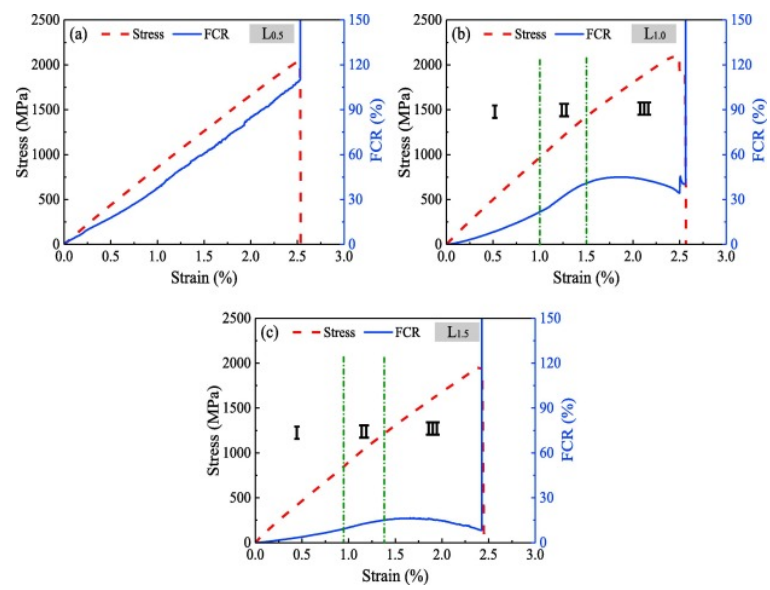

Fig. 10. Responses of FCR and stress to strain under monotonic tensile loading for (a) Lo.5, (b) L 1.0 and (c) L1.5. (For interpretation of the references to colour in this figure legend, the reader is referred to the web version of this article.)

The macroscopic damages generally include matrix cracks, interfacial debonding between the fiber and the matrix, transverse cracks, longitudinal splitting, delamination, as well as local fiber breakage and pull-out [6]. The optical and SEM images of damage initiation and accumulation in CNFs/BFRP laminates under monotonic tensile loading are shown in Fig. 11, and Fig. 12 illustrates schematically the damage evolution of CNFs/BFRP laminates. In Stage I, the FCR-strain curves present an approximate linear relationship (Fig. 10b and c), corresponding to almost no damage being initiated or a few small matrix microcracks (Fig. 11a) arising from preexisting flaws. During Stage II, with the gradual increase of the strain, the FCR values start to deviate from the initial linear curve and the slope of the FCR-strain curves increase. In this stage, the microcracks grow into transverse cracks and fiber-matrix interfacial debonding (shown in Fig. 11b) was observed. The transverse cracks and interfacial debonding probably induce more destruction of conductive networks in the laminates, which can be used to explain the FCR responses in Stage II shown in Fig. 10b and c. When the curves enter into Stage III, the FCR values increase slowly first and then decrease with the increasing deformation, and the final sharp increase of FCR indicates the final fractured of the sample. Besides the transverse cracks and interfacial debonding, the longitudinal splitting (Fig. 11C), delamination, and local basalt fiber breakage (Fig. 11d) along load direction will take place during this stage. Overall, these factors could further break up the conduction paths, leading to the increase of resistivity in the laminates. However, it is known that the value of Poisson's ratio will increase with the stress beyond the elastic region [29], which in turn reformed the conductive paths. Moreover, when the CNFs/BFRP laminates were in Stage III, their internal CNFs/epoxy composites entered the obvious plastic region according to the stress-strain curves shown in Fig. $9 \mathrm{~b}$ and c. Therefore, the Poisson's effect of matrix becomes more obvious in Stage III, which will in turn facilitate the change of woven yarn geometry. However, the damage inside the composites is complex and quite difficult to be observed during 
Stage III. Combining with the FCR-strain curves in Stage III, it can be considered that the Poisson's contraction of the matrix and the resulted change of yarn geometry possibly play a considerable role on the close of microcracks [29], [43]. In addition, the reorientation of CNFs resulted from the increased strain is also beneficial to the reformation of conductive networks [44]. Therefore, during Stage III, there are two opposite factors mainly influencing the change of electrical resistivity: damage accumulation causes the increase of resistivity, whereas Poisson's contraction of matrix induced the formations of new conductive networks leads to the decrease of resistivity. However, the latter has a much greater effect on the resistivity change than the former, which can be used to explain the phenomenon of a slight increase and then decrease of the FCR values during this stage.
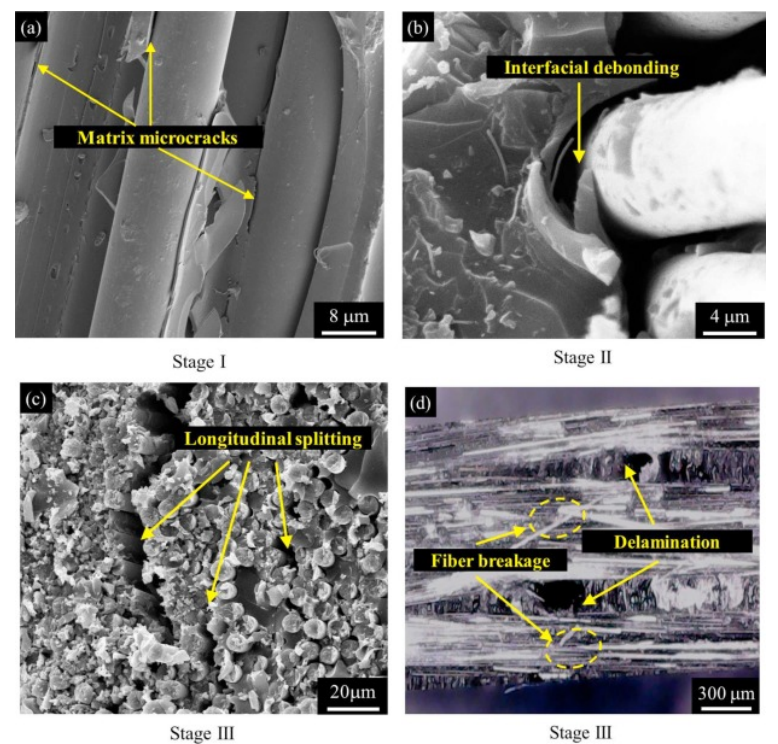

Fig. 11. SEM and optical images of the damage initiation and accumulation in CNFs/BFRP laminates: (a) epoxy matrix microcracks; (b) fiber-matrix interfacial debonding; (c) longitudinal splitting and (d) delamination and fiber breakage. (For interpretation of the references to colour in this figure legend, the reader is referred to the web version of this article.)

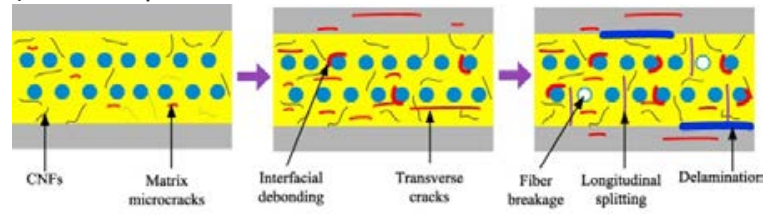

(a) (b)

(c)

Fig. 12. Illustration of damage evolution of CNFs/BFRP laminates: (a) initiation of matrix microcracks; (b) transverse cracks and interfacial debonding; (c) longitudinal splitting, delamination and fiber breakage. (For interpretation of the references to colour in this figure legend, the reader is referred to the web version of this article.)

\subsubsection{Strain self-sensing under constant cyclic tensile loading}

The descriptions in Section 3.4.1 have demonstrated that CNFs/BFRP laminates have the self-sensing capability of damage under monotonic tensile loading. In order to simulate realistic loading conditions and verify the stability and repeatability of the strain self-sensing capability of CNFs/BFRP laminates, constant amplitude cyclic loadings were applied to the specimens. Pre-tension treatment for each specimen was carried out by applying cyclic preconditioning strain before cyclic loading test in order to achieve a stable conductive state. The maximum strains of cyclic loadings for CNFs/EP composites and CNFs/BFRP laminates were $0.5 \%$ and $1.0 \%$, respectively, to keep the deformation of the specimens in the elastic region (shown in Figs. 9 and $\underline{10}$ ), which corresponds to the stage of almost no damage in specimens.

Fig. 13, Fig. 14 present the typical strain self-sensing responses of the CNFs/epoxy composites and CNFs/BFRP laminates under cyclic tensile loading, respectively. It is observed from Figs. 13a and 14a that the instantaneous 
responses of FCR closely follow the changes of the strain, which reveals that the resistivities of the specimens vary synchronously with the applied strains. The values of the FCR steadily increase with the increasing strains and then gradually decrease during unloading. In the subsequent stretching-releasing cycles, both of CNFs/epoxy composites and CNFs/BFRP laminates essentially recover their resistivity after releasing, indicating their excellent repeatability. It can be seen from the FCR-strain plots in Figs. 13b and $14 \mathrm{~b}$ that specimens containing more CNFs have clearer linear relationship and smaller hysteresis, which indicates that the stain selfsensing ability of the specimens with more CNFs is more stable than that of specimens containing less CNFs. The strain self-sensing behavior is based on the principle of the piezoresistive properties of the nanocomposites, which is due to the nanoscale structural change in the percolation and corresponds to a stochastic separation of the conducting pathways because of the increased matrix strain. Therefore, the reversible leaving/approaching of the CNFs during the constant amplitude cyclic loading causes the increase/decrease of the resistivity.
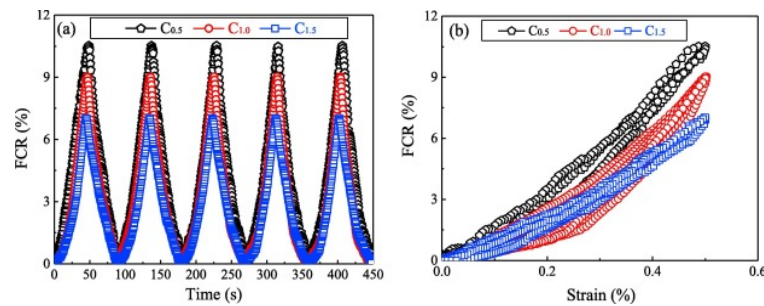

Fig. 13. Cyclic tensile loading responses of CNFs/epoxy laminates containing 0.5 wt\%, 1.0 wt\% and 1.5 wt\% of CNFs: (a) FCR vs time; (b) FCR vs strain. (For interpretation of the references to colour in this figure legend, the reader is referred to the web version of this article.)
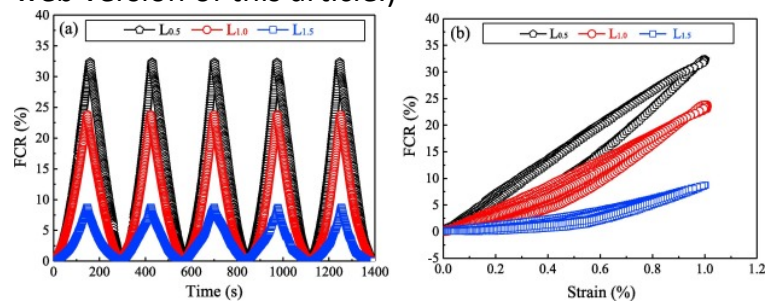

Fig. 14. Cyclic tensile loading responses of CNFs/BFRP laminates containing 0.5 wt\%, 1.0 wt\% and 1.5 wt\% of CNFs: (a) FCR vs time; (b) FCR vs strain. (For interpretation of the references to colour in this figure legend, the reader is referred to the web version of this article.)

Interestingly, FCR exhibited a nonlinear variation at the beginning and the end of each loading cycle, whereas an approximately linear relationship was observed under lager strain as shown in Figs. 13a and 14a. This is attributed to the different conductive mechanisms during different deformations of the specimens. It has been discussed in Section 3.2.2 that there are two types of conductive mechanisms, i.e., tunneling conduction theory and contacting conduction theory, affecting the resistivity of the specimens. However, electrons can tunnel through a polymer matrix if the distance between the adjacent CNFs is less than the tunneling distance (of the order 5-50 nm) [45]. Therefore, the tunneling conduction plays a non-negligible role in the resistivity change of the specimen when the deformation is small. The random distribution and possible tunneling paths between adjacent CNFs have been examined using SEM, as shown in Fig. 15a. Moreover, Fig. 15b presents the model for evaluating tunneling resistance in the resistor network under cyclic tensile loading. The tunneling resistance between two neighboring CNFs can be approximately estimated as [46]:

(4) $R_{\text {tunnel }}=\frac{V}{A J}=\frac{h^{2} d}{A e^{2} \sqrt{2 m \lambda}} \exp \left(\frac{4 \pi d}{h} \sqrt{2 m \lambda}\right)$

where $V$ is the electrical potential difference; $A$ is the cross-sectional area of the tunnel (the cross sectional area of CNF is approximately used here); $J$ is the tunneling current density; $h$ is Planck's constant; $d$ is the distance between CNTs; $e$ is the quantum of electricity; $m$ is the mass of electron; and $\lambda$ is the height of barrier (for epoxy 
matrix, 0.5-2.5 eV). According to Eq. (4), the exponential function indicates that a slight increase of $d$ causes a significant increase of tunneling resistance. Therefore, a nonlinear variation of FCR with changing tunneling gaps due to changing strain is reasonable, especially at the beginning zone and the end zone of each cycle shown in Figs. 13a and 14a.

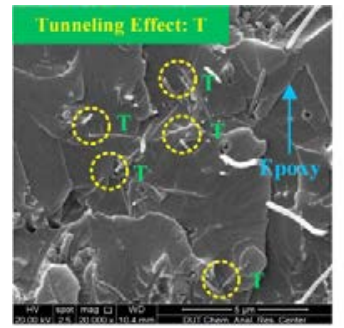

(a)

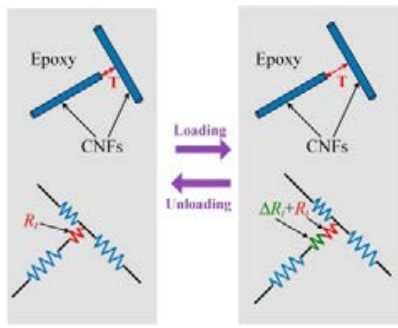

(b)

Fig. 15. Tunneling effect: (a) SEM image of possible tunneling effect among CNFs in the nanocomposites; (b) Model of tunneling resistance in the resistor network under cyclic tensile loading. (For interpretation of the references to colour in this figure legend, the reader is referred to the web version of this article.)

When the distances between adjacent CNFs exceed the tunneling gaps due to the increasing deformation of the epoxy matrix, the tunneling conduction will gradually disappear, suggesting the variation of resistivity is mainly influenced by the contacting conduction. Fig. 16a shows the SEM image of the contacting conduction paths between adjacent CNFs. Fig. 16b presents the model for evaluating the contacting resistance of the resistor network under cyclic tensile loading. For a CNF with two contacting points $i$ and $j$, the resistance $R_{i j}$ between $i$ and $j$ can be evaluated as [47]:

(5) $R_{i j}=\frac{L_{i j}}{\sigma_{C N F} S_{C N F}}$

where $L_{i j}$ is the distance between two contacting points, $\sigma_{C N F}$ and $S_{C N F}$ are the electrical conductivity and crosssectional area of the CNF, respectively. A linear relationship between $R_{i j}$ and $L_{i j}$ is obtained from the equation. Therefore, the resistance $R_{i j}$ increases linearly with the increasing distance of the two contacting points during tensile loading. This may be the main reason that FCR exhibits an approximately linear change under lager strain of each cycle.

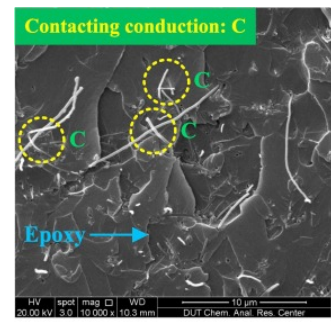

(a)

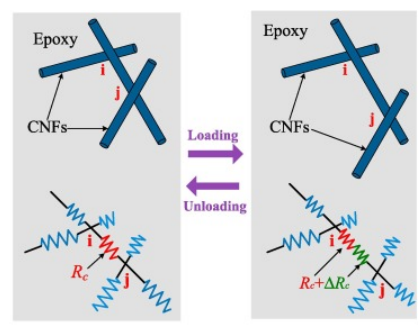

(b)

Fig. 16. Contacting conduction: (a) SEM image of contacting conduction among CNFs in the nanocomposites; (b) Model of contacting resistance in the resistor network under cyclic tensile loading. (For interpretation of the references to colour in this figure legend, the reader is referred to the web version of this article.)

Gauge factor (GF), also called strain sensitivity coefficient, which is defined as the ratio between the relative change of electrical resistance $\left(\Delta R / R_{0}\right)$ and the strain $(\varepsilon)$, is given by Eq. (6) [48], [49].

(6) $\mathrm{GF}=\frac{\Delta R / R_{0}}{\varepsilon}=\frac{\mathrm{FCR}}{\varepsilon}$ 
where $\Delta R$ is the electrical resistance increment, and $R_{0}$ is the initial electrical resistance without loading. The values of GF obtained by linear regression analysis of the data according to Eq. (6) are shown in Fig. 17. It should be noted that the data used for this analysis are obtained from Figs. 13b and 14b. Every column chart shows the average values with error bars obtained from three samples. As shown in Fig. 17a and b, for CNFs/epoxy composites and CNFs/BFRP laminates, the values of GF are affected by the strain and the CNFs content. Especially, the specimens with lower CNFs fraction exhibit higher GF values under same applied strain. Although the specimen with the lowest content of CNFs possesses the highest sensitivity, it has the lowest linearity of the curves (shown in Figs. 13b and $\underline{14 b}$ ). Therefore, a trade-off has to be made between the sensitivity and the linearity. Moreover, the values of GF depend on the nanocomposites themselves, the types and the contents of conductive fillers, the types of the matrix and reinforced fiber fabric. The gauge factors of CNFs/epoxy composites and CNFs/BFRP laminates are sufficient for their strain monitoring.
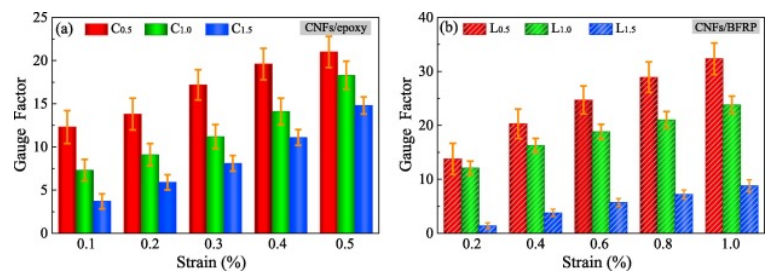

Fig. 17. Gauge factor of (a) CNFs/epoxy composites and (b) CNFs/BFRP laminates under constant cyclic tensile loading. (For interpretation of the references to colour in this figure legend, the reader is referred to the web version of this article.)

\section{Conclusions}

Different contents of CNFs were dispersed into epoxy matrix via mechanical stirring and ultrasonic treatment to prepare the electrically conductive CNFs/epoxy composites. The CNFs/BFRP laminates were fabricated by infusing the CNFs/epoxy composites into basalt fiber fabrics using the wet lay-up technique. The electrical and self-sensing properties of CNFs/BFRP laminates and CNFs/epoxy composites were investigated. The conduction mechanisms based on the tunnel conduction and percolation conduction theories as well as the damage evolution were also explored. The following conclusions can be drawn from this study:

(1) SEM results showed that most CNFs can be uniformly dispersed in the epoxy matrix and penetrate the basalt fiber bundles, forming conductive networks throughout the BFRP laminates.

(2) The resistivities of CNFs/BFRP laminates and CNFs/epoxy composites showed same change rule with the change of CNFs contents, which demonstrated that CNFs/BFRP laminates' conductive networks were all from the CNFs/epoxy composites. Moreover, the percolation threshold values of CNFs/epoxy composites and CNFs/BFRP laminates are $0.34 \mathrm{wt} \%$ and $0.32 \mathrm{wt} \%$ based on the typical power law, respectively.

(3) Temperature compensation is necessary due to the high temperature dependence of the CNFs/BFRP laminates. The proposed compensation circuit with a half bridge configuration can effectively eliminate the influence of temperature on sensing signals of CNFs/BFRP laminates.

(4) The BFRP laminates containing $1.0 \mathrm{wt} \%$ and $1.5 \mathrm{wt} \%$ of CNFs have good damage self-sensing ability to monitor the damage evolution under monotonic tensile loading until their failure. Their FCR-strain curves can be classified into three stages, corresponding to different damage modes, i.e., matrix microcracks, transverse cracks, interfacial debonding, longitudinal splitting, delamination and basalt fiber breakage.

(5) Analysis of the FCR responses to strain in the elastic region under cyclic tensile loading confirmed the stable and repeatable strain self-sensing capacity of CNFs/BFRP laminates. However, the nonlinear variation of FCR at the beginning and the end of each cycle is attributed to the effect of tunneling conduction at small deformation of CNFs/BFRP laminates. 


\section{Acknowledgments}

This work was supported by the National Key R\&D Program of China (Project No. 2017YFC0703008), the National Natural Science Foundation of China (Project No. 51778102), the Fundamental Research Funds for the Central Universities (Project No. DUT18LK35) and the State Scholarship Fund of China (Project No. 201706060249).

\section{References}

[1] H. Zhang, Y. Liu, M. Kuwata, E. Bilotti, T. Peijs Improved fracture toughness and integrated damage sensing capability by spray coated CNTs on carbon fibre prepreg Compos Part A Appl Sci Manuf, 70 (2015), pp. 102-110

[2] T. Mohammadi, B. Wan, K. Harries, M. Sweriduk Bond behavior of FRP/concrete in presence of intermediate crack debonding failure J Compos Constr, 21 (5) (2017), p. 04017018 [12 pp]

[3] Y. Bai, J. Dai, J. Teng Buckling of steel reinforcing bars in FRP-confined RC columns: an experimental study Constr Build Mater, 140 (2017), pp. 403-415

[4] T.H. Loutas, V. Kostopoulos Health monitoring of carbon/carbon, woven reinforced composites. Damage assessment by using advanced signal processing techniques. Part I: acoustic emission monitoring and damage mechanisms evolution Compos Sci Technol, 69 (2009), pp. 265-272

[5] H. Hatta, M.S. Aly-Hassan, Y. Hatsukade, S. Wakayama, H. Suemasu, N. Kasai Damage detection of C/C composites using ESPI and SQUID techniques Compos Sci Technol, 65 (2005), pp. 1098-1106

[6] L. Gao, E.T. Thostenson, Z. Zhang, T.-W. Chou Sensing of damage mechanisms in fiber-reinforced composites under cyclic loading using carbon nanotubes Adv Funct Mater, 19 (2009), pp. 123-130

[7] A.E. Refai Durability and fatigue of basalt fiber-reinforced polymer bars gripped with steel wedge anchors J Compos Constr, 17 (6) (2013), pp. 1-11

[8] G. Landucci, F. Rossi, C. Nicolella, S. Zanelli Design and testing of innovative materials for passive fire protection Fire Saf J, 44 (2009), pp. 1103-1109

[9] V. Lopresto, C. Leone, I. De lorio Mechanical characterisation of basalt fibre reinforced plastic Compos Part B Eng, 42 (2011), pp. 717-723

[10] Y. Li, Y. Wang, J. Ou Mechanical behavior of BFRP-steel composite plate under axial tension Polymers, 6 (2014), pp. 1862-1876

[11]Z. Lu, G. Xian Combined effects of sustained tensile loading and elevated temperatures on the mechanical properties of pultruded BFRP plates Constr Build Mater, 150 (2017), pp. 310-320

[12] Y. Wang, G. Chen, B. Wan, H. Lin, J. Zhang Behavior of innovative circular ice filled steel tubular stub columns under axial compression Constr Build Mater, 171 (2018), pp. 680-689

[13] B. Hao, T. Förster, E. Mäder, P.C. Ma Modification of basalt fibre using pyrolytic carbon coating for sensing applications Compos Part A Appl Sci Manuf, 101 (2017), pp. 123-128

[14] J. Sim, C. Park, D.Y. Moon Characteristics of basalt fiber as a strengthening material for concrete structures Compos Part B Eng, 36 (2005), pp. 504-512

[15] B. Wei, H. Cao, S. Song Degradation of basalt fibre and glass fibre/epoxy resin composites in seawater Corros Sci, 53 (2011), pp. 426-431

[16] Y. Wang, R. Chang, G. Chen Strain and damage self-sensing properties of carbon nanofibers/carbon fiberreinforced polymer laminates Adv Mech Eng, 9 (2017), pp. 1-11

[17] R. Schueler, S.P. Joshi, K. Schulte Damage detection in CFRP by electrical conductivity mapping Compos Sci Technol, 61 (2001), pp. 921-930

[18] X. Wang, D.D.L. Chung Continuous carbon fibre epoxy-matrix composite as a sensor of its own strain Smart Mater Struct, 5 (1996), pp. 796-800 
[19] S. Wang, D.D.L. Chung Self-sensing of flexural strain and damage in carbon fiber polymer-matrix composite by electrical resistance measurement Carbon NY, 44 (2006), pp. 2739-2751

[20] X. Wang, D.D.L. Chung Real-time monitoring of fatigue damage and dynamic strain in carbon fiber polymer-matrix composite by electrical resistance measurement Smart Mater Struct, 6 (1997), pp. 504508

[21] N. Hu, Z. Masuda, G. Yamamoto, H. Fukunaga, T. Hashida, J. Qiu Effect of fabrication process on electrical properties of polymer/multi-wall carbon nanotube nanocomposites Compos Part A Appl Sci Manuf, 39 (2008), pp. 893-903

[22] Y. Wang, Y. Wang, B. Wan, B. Han, G. Cai, Z. Li Properties and mechanisms of self-sensing carbon nano fibers/epoxy composites for structural health monitoring Compos Struct, 200 (2018), pp. 669-678

[23] A. Ferreira, P. Cardoso, D. Klosterman, J.A. Covas, F. Hattum, F. Vaz, et al. Effect of filler dispersion on the electromechanical response of epoxy/vapor-grown carbon nanofiber composites Smart Mater Struct, 21 (2012), pp. 75008-75016

[24] R. Liu, H. Xiao, H. Li, L. Sun, Z. Pi, G. Waqar, et al. Effects of nano-SiO ${ }_{2}$ on the permeability-related properties of cement-based composites with different water/cement ratios J Mater Sci, 53 (2018), pp. 4974-4986

[25] J. Luo, Z. Duan, G. Xian, Q. Li, T. Zhao Damping performances of carbon nanotube reinforced cement composite Mech Adv Mater Struct, 22 (2015), pp. 224-232

[26] W. Li, C. Long, V.W.Y. Tam, C.S. Poon, Duan W. Hui Effects of nano-particles on failure process and microstructural properties of recycled aggregate concrete Constr Build Mater, 142 (2017), pp. 42-50

[27] I. Marriam, F. Xu, M. Tebyetekerwa, Y. Gao, W. Liu, X. Liu, et al. Synergistic effect of CNT films impregnated with CNT modified epoxy solution towards boosted interfacial bonding and functional properties of the composites Compos Part A App/ Sci Manuf, 110 (2018), pp. 1-10

[28] X. Wang, S. Meng, M. Tebyetekerwa, Y. Li, J. Pionteck, B. Sun, et al. Highly sensitive and stretchable piezoresistive strain sensor based on conductive poly(styrene-butadiene-styrene)/few layer graphene composite fiber Compos Part A App/ Sci Manuf, 105 (2018), pp. 291-299

[29] W. Li, D. He, Z. Dang, J. Bai In situ damage sensing in the glass fabric reinforced epoxy composites containing CNT-Al ${ }_{2} \mathrm{O}_{3}$ hybrids Compos Sci Technol, 99 (2014), pp. 8-14

[30] L. Gao, T.W. Chou, E.T. Thostenson, Z. Zhang A comparative study of damage sensing in fiber composites using uniformly and non-uniformly dispersed carbon nanotubes Carbon NY, 48 (2010), pp. 3788-3794

[31] I.W. Nam, S.M. Park, H.K. Lee, L. Zheng Mechanical properties and piezoresistive sensing capabilities of FRP composites incorporating CNT fibers Compos Struct, 178 (2017), pp. 1-8

[32] N.D. Alexopoulos, C. Bartholome, P. Poulin, Z. Marioli-Riga Structural health monitoring of glass fiber reinforced composites using embedded carbon nanotube (CNT) fibers Compos Sci Technol, 70 (2010), pp. 260-271

[33] S. Gao, R. Zhang, J. Zhang, J. Liu, E. Mader Glass fibers with carbon nanotube networks as multifunctional sensors Adv Funct Mater, 20 (2010), pp. 1885-1893

[34] A.O. Monteiro, A. Loredo, P.M.F.J. Costa, M. Oeser, P.B. Cachim A pressure-sensitive carbon black cement composite for traffic monitoring Constr Build Mater, 154 (2017), pp. 1079-1086

[35] D. Stauffer, A. Aharony, S. Redner Introduction to percolation theory Taylor \& Francis (1992) [122]

[36] P. Sheng, E.K. Sichel, J.I. Gittleman Fluctuation induced tunneling conduction in carbon polyvinylchloride composites Phys Rev Lett, 40 (1978), pp. 1197-1200

[37] B.E. Kilbride, J.N. Coleman, J. Fraysse, P. Fournet, M. Cadek, A. Drury, et al. Experimental observation of scaling laws for alternating current and direct current conductivity in polymer-carbon nanotube composite thin films J Appl Phys, 92 (2002), pp. 4024-4030

[38] L. He, S.C. Tjong Low percolation threshold of graphene/polymer composites prepared by solvothermal reduction of graphene oxide in the polymer solution Nanoscale Res Lett, 8 (2013), pp. 2-8 
[39] L. Bai, S. He, J.W. Fruehwirth, A. Stein, C.W. Macosko, X. Cheng Localizing graphene at the interface of continuous polymer blends: morphology, rheology, and conductivity of continuous conductive polymer composites J Rheol, 61 (2017), pp. 575-587

[40] S. Luo, T. Liu, S.M. Benjamin, J.S. Brooks Variable range hopping in single-wall carbon nanotube thin films: a processing-structure-property relationship study Langmuir, 29 (2013), pp. 8694-8702

[41] B. Hao, Q. Ma, S. Yang, E. Mäder, P.C. Ma Comparative study on monitoring structural damage in fiberreinforced polymers using glass fibers with carbon nanotubes and graphene coating Compos Sci Technol, 129 (2016), pp. 38-45

[42] J.T. Shen, S.T. Buschhorn, J.T.M. De Hosson, K. Schulte, B. Fiedler Pressure and temperature induced electrical resistance change in nano-carbon/epoxy composites Compos Sci Technol, 115 (2015), pp. 1-8

[43] K.J. Kim, W.R. Yu, J.S. Lee, L. Gao, E.T. Thostenson, T.W. Chou, et al. Damage characterization of 3D braided composites using carbon nanotube-based in situ sensing Compos Part A Appl Sci Manuf, 41 (2010), pp. 1531-1537

[44] W. Li, J. Yuan, A. Dichiara, Y. Lin, J. Bai The use of vertically aligned carbon nanotubes grown on SiC for in situ sensing of elastic and plastic deformation in electrically percolative epoxy composites Carbon, 50 (2012), pp. 4291-4301

[45] M. Amjadi, Y.J. Yoon, I. Park Ultra-stretchable and skin-mountable strain sensors using carbon nanotubesEcoflex nanocomposites Nanotechnology, 26 (2015)

[46] Hu.N. Alamusi, H. Fukunaga, S. Atobe, Y. Liu, J. Li Piezoresistive strain sensors made from carbon nanotubes based polymer nanocomposites Sensors, 11 (2011), pp. 10691-10723

[47] N. Hu, Y. Karube, C. Yan, Z. Masuda, H. Fukunaga Tunneling effect in a polymer/carbon nanotube nanocomposite strain sensor Acta Mater, 56 (2008), pp. 2929-2936

[48] S. Luo, W. Obitayo, T. Liu SWCNT-thin-film-enabled fiber sensors for lifelong structural health monitoring of polymeric composites-From manufacturing to utilization to failure Carbon NY, 76 (2014), pp. 321329

[49] H. Xiao, M. Liu, G. Wang Anisotropic electrical and abrasion-sensing properties of cement-based composites containing aligned nickel powder Cement Concrete Comp, 87 (2018), pp. 130-136 